\title{
Oxygen consumption, heart rate and oxygen pulse associated with selected exercise-to-music class elements
}

\author{
Peter Abernethy PhD and Paul Batman MSc* \\ Department of Human Movement Studies, The University of Queensland, Brisbane, Australia and *Human \\ Performance Laboratory, School of Sport and Leisure Studies, The University of New South Wales, Oatley, \\ Australia
}

The purpose of the investigation was to determine the relative oxygen consumption $\left(\dot{V}_{\mathrm{O}_{2}}\right)$, heart rate and oxygen pulse associated with the constituent elements of an exercise-to-music class. Six women exercise-to-music leaders with a mean(s.d.) age, weight and height of $33.2(5.2)$ years, $51.0(2.8) \mathrm{kg}$ and $157.9(5.6) \mathrm{cm}$ respectively, completed five distinct exercise-to-music movement elements. The movement elements were of a locomotor (circuit, jump and low impact) and callisthenic (prone and side/supine) nature. The movement elements were distinguishable from one another in terms of their movement patterns, posture and tempo. Relative $\dot{V}_{2}$ values were greatest for the circuit element $\left(40.6 \mathrm{ml} \mathrm{kg}^{-1} \mathrm{~min}^{-1}\right)$ and least for the side/supine element $\left(20.0 \mathrm{ml} \mathrm{kg}^{-1} \mathrm{~min}^{-1}\right)$. The differences in $\dot{V}_{2}$ between the locomotor and callisthenic elements were significant (circuit $\approx$ jump $\approx$ low impact $>$ prone $\approx$ side/supine). However, effect size data suggested that the differences between the low impact and jump elements and the prone and side/supine elements were of practical significance (circuit $\approx$ jump $>$ low impact $>$ prone $>$ side/supine). With a single exception similar parametric statistics and effect size trends were identified for absolute heart rate. Specifically, the heart rate associated with the low impact element was not significantly greater than the prone element. The oxygen pulse associated with the locomotor elements was significantly greater than the callisthenic elements (circuit $\approx$ jump $\approx$ low impact $>$ prone $>$ side/supine). This suggested that heart rate may be an inappropriate index for making comparisons between exercise-to-music elements. Reasons for differences in oxygen uptake values between movement elements are discussed.

Keywords: Exercise to music, class elements, $\dot{V}_{\mathrm{O}_{2}}$, heart rate, oxygen pulse

There seems little doubt that aerobic dance or exercise to music can be a successful means of aerobic conditioning ${ }^{1-8}$. However, few of these investigations distinguish between the types of movement used in the exercise-to-music classes ${ }^{1,2,4,6,7,9}$. Exer-

Address for correspondence: Peter J. Abernethy PhD, Department of Human Movement Studies, The University of Queensland, Brisbane, Queensland 4072, Australia

(C) 1994 Butterworth-Heinemann Ltd 0306-3674/94/010043-04 cise to music is not a single movement pattern, but an aggregate of callisthenic and dance patterns ${ }^{10}$. Thus, when analysing an exercise-to-music programme, some consideration should be given to the movement elements within the class. To date research in relation to class structure has concentrated on the methods and tempo of locomotion ${ }^{2-4,6-8}$. However, little attention has been focused on the callisthenic component of exercise-to-music classes.

Additionally, the potential of exercise-to-music to induce an aerobic training effect varies with the participant. For example, Moore et al. ${ }^{11}$ reported that 20-30 min of low-impact aerobic dance performed four times a week produced a training effect in individuals with no history of regular activity, but not in individuals who had. Goss et al. ${ }^{12}$ reported that men, with an average $\dot{V}_{2}$ max of $55 \mathrm{ml} \mathrm{kg}^{-1} \mathrm{~min}^{-1}$, used both anaerobic and aerobic metabolic pathways when completing bench-stepping tasks similar to those found in community fitness settings. This illustrates that the appropriateness of a given exercise regimen within a commercial setting differs between individuals. Consequently, when designing an exercise prescription involving exercise to music, both the structure of the prescription and the aerobic capacity of an individual should be considered.

The purpose of this study was to determine the $\dot{V} \mathrm{O}_{2}$, heart rate and oxygen pulse values associated with typical locomotor (circuit, jump and low-impact) and callisthenic (prone and side/supine) activities within exercise-to-music classes.

\section{Subjects and methods}

Six women, exercise leaders with a mean(s.d.) age, height and weight of $33.2(5.2)$ years, $157.9(5.6) \mathrm{cm}$ and $51.0(2.8) \mathrm{kg}$ respectively, participated in the investigation. Experienced exercise leaders were recruited as these individuals would perform the movements patterns in the most efficient manner. The study conformed to the Australian National Health and Medical Research Council's guidelines for research with human subjects. Testing was conducted at the Human Performance Laboratory of The University of New South Wales. 


\section{Procedures}

Subjects were tested on five separate occasions. During each session, participants performed one element of an exercise-to-music class. The five exercise-to-music class elements were the circuit, jump, low-impact, prone and side/supine elements. The order in which participants undertook the class elements was randomized to minimize any order effect. The activities, their sequencing and accompanying music were developed and chosen by a panel of six qualified and experienced instructors (i.e. they had been designing and implementing sessions for at least 5 years). The panel classified the activities as being appropriate for individuals of intermediate (average) fitness.

Each class element was of $4 \mathrm{~min}$ duration. There were two callisthenic or floor elements: prone and side/supine. In these elements at least part of one arm and one leg was in contact with the floor at all times. The prone and side/supine elements were distinguishable from one another by the posture adopted in the respective elements. Low-impact activity was defined as upright activity in which one foot was always in contact with the ground. The jump and circuit elements were upright, high-impact elements (i.e. both feet could be off the ground at the same time). The jump element was centred on jumping type movements, while the circuit element was based on running movements in combination with a mixture of the other class elements. Rhythmic arm activity was performed with all upright posture elements. The tempo of the music for the circuit, jump, low-impact, prone and side/supine elements was 164, 172, 152, 144 and 132 beats $\min ^{-1}$ respectively. Each class element was initially video recorded to ensure that the activities within each element were constant across all measurement occasions.

On arrival at the laboratory the subjects' weights were measured by standard means. The subjects then rested for $15 \mathrm{~min}$ before assessment. In this period resting heart rate was assessed and the participants watched a video recording of the particular class element to be undertaken. Subjects wore typical exercise-to-music clothes: nylon leotards and tights, cotton singlet, socks and shoes. The laboratory had temperatures and humidity values between 16 and $22^{\circ} \mathrm{C}$ and 40 and $60 \%$ respectively. During testing $\dot{V} \mathrm{O}_{2}$, oxygen pulse and heart rate information were recorded. These parameters were measured for the
3 min before and after each class element. Heart rate (Polar Electra Sports Tester; Polar Electronics, Kempele, Finland) and oxygen consumption values (Mijnhardt 4 Oxycon; Mijnhardt, Odijk, Holland) were measured and recorded every 15 and $30 \mathrm{sec}$ respectively. The Mijnhardt 4 Oxycon was calibrated using room air (carbon dioxide: $0.00 \%$ and oxygen: $20.9 \%$ ) and a known calibration gas (oxygen: $0 \%$ and carbon dioxide: $4.1 \%$ ). Testing, with the exception of two subjects, was completed on separate days. During data analysis only the last 2 min of each class element were considered.

\section{Statistics}

Three dependent variables, oxygen consumption, heart rate and oxygen pulse, were assessed in every class element (jump, circuit, low-impact, prone side/supine). One-factor repeated measures analyses of variance (ANOVAs) were used to compare values for these variables during each of the class elements. A 0.05 level of significance was adopted. Scheffé's $F$ test was used in post hoc analyses. Differences between means may be statistically significant without necessarily having any practical significance. Conversely, large absolute differences between means may not reach statistical significance because of small sample size. To overcome these problems, and to facilitate cross-study comparisons, results have also been reported in terms of effect size (ES). ESs of approximately $0.2,0.5$ and 0.8 were categorized as small, moderate and large respectively ${ }^{13}$. The standard deviation used in the ES computation was determined in the manner described by Hedges and Olkin ${ }^{14}$.

\section{Results}

The relative $\dot{V} \mathrm{O}_{2}$ of class elements ranged from $20.0 \mathrm{ml} \mathrm{kg}^{-1} \mathrm{~min}^{-1}$ (side/supine) to $40.6 \mathrm{ml} \mathrm{kg}^{-1} \mathrm{~min}^{-1}$ (circuit; Table 1). For the callisthenic elements $\dot{V}_{\mathrm{O}_{2}}$ was significantly less than for the locomotor components. Within the locomotor and callisthenic groupings the differences were not statistically significant (circuit $\approx$ jump $\approx$ low impact $>$ prone $\approx$ side/supine). However, when the $\dot{V} \mathrm{O}_{2}$ values of individual class elements were contrasted using ESs (Table 1) a different picture was derived to that which arose from the post hoc analyses. Specifically, there were

Table 1. $\dot{V}_{\mathrm{O}_{2}}$, heart rate and oxygen pulse for the circuit, jump, low-impact, prone and side/supine class elements. The differences between class elements were also estimated by effect size (ES)

\begin{tabular}{|c|c|c|c|c|c|c|c|c|c|}
\hline & Circuit & & Jump & & Low impact & & Prone & & Side/supine \\
\hline $\begin{array}{l}\dot{V}_{\mathrm{O}_{2}}\left(\mathrm{ml} \mathrm{kg}^{-1} \mathrm{~min}^{-1}\right)^{*} \\
\mathrm{ES \S}\end{array}$ & $40.6(3.0) t \ddagger$ & 0.39 & $39.2(4.2) \dagger \ddagger$ & 1.22 & $35.8(4.7)+\ddagger$ & 2.80 & $26.0(1.4)$ & 4.76 & $20.0(1.1)$ \\
\hline $\begin{array}{l}\left.\text { Heart rate (beats } \min ^{-1}\right)^{*} \\
\text { ES }\end{array}$ & $159(8)+\ddagger$ & 0.01 & $159(12)+\ddagger$ & 0.77 & $148(15) \dagger$ & 0.88 & $135(14)$ & 0.71 & $123(19)$ \\
\hline $\begin{array}{l}\text { Oxygen pulse }\left(\mathrm{ml} \mathrm{beat}^{-1}\right)^{*} \\
\text { ES }\end{array}$ & $13.1(1.3) \dagger \ddagger$ & 0.44 & $12.5(1.3) t \ddagger$ & 0.03 & $12.5(1.4) \dagger \ddagger$ & 0.22 & $9.9(0.9) \dagger$ & 1.46 & $8.4(1.1)$ \\
\hline
\end{tabular}

*Values are mean(s.d.); †Significantly different to side/supine element $(P<0.05)$; analysis of variance); $¥$ Significantly different to prone element $(P<0.05$; analysis of variance); $\S E S: 0.2$, a small difference; 0.5 , a moderate difference; 0.8 , a large difference 
moderately large ESs between the low-impact element and the circuit and jump elements $(1.22 ; 0.76)$; and between the prone and side/supine tracks (4.76; i.e. circuit $\approx$ jump $>$ low impact $>$ prone $>$ side supine).

Heart rate ranged from 123 beats $\min ^{-1}$ for the side/supine element to 159 beats $\min ^{-1}$ for the circuit and jump elements respectively (Table 1). The heart rates for the circuit and jump elements were significantly greater than for the floor elements. The low-impact element had a greater heart rate than the side/supine element. The two floor elements had heart rates which were not statistically different. There were moderately large ESs between the low-impact element and the circuit and jump elements (0.87, 0.77; Table 1); the low impact and prone elements $(0.88)$; and the prone and side and supine elements (0.71). Thus, ES data suggested that there were marked differences between the heart rates of all elements, with the exception of the jump and circuit elements (circuit $\approx$ jump $>$ low impact $>$ prone $>$ side/supine).

The circuit $\left(13.07 \mathrm{ml}^{\text {beat }}{ }^{-1}\right)$ and side/supine $\left(8.41 \mathrm{ml} \mathrm{beat}^{-1}\right)$ elements had the highest and lowest oxygen pulses respectively (Table 1). The oxygen pulse was significantly greater for the upright locomotor elements than the floor elements. The prone element had a greater oxygen pulse than the side/supine element (circuit $\approx$ jump $\approx$ low impact $>$ prone $>$ side/supine). The ESs describing the differences between the elements mirrored that of the post hoc analyses (Table 1).

\section{Discussion}

The oxygen consumption, heart rate and oxygen pulse were not similar for all class elements. Consequently, the potential for aerobic conditioning differed between class elements.

$\dot{V} \mathrm{O}_{2}$, heart rate and oxygen pulse data were analysed using inferential and ES statistics. Many readers of research presume that a significant $P$ value arising from the manipulation of the independent variable indicates practical significance ${ }^{15}$. However, Thomas et al. ${ }^{15}$ illustrated that sample size and not the manipulation of the independent variable often determined whether a significant $P$ was attained. Consequently, Thomas et al. ${ }^{15}$ requested that ES and $P$ values be reported so that the reader could assess the 'meaningfulness of the treatment'. In the case of $\dot{V} \mathrm{O}_{2}$ and heart rate data in this investigation, it appeared that the inferential procedures on occasion did not detect differences which were of practical significance $^{15}$. This discrepancy between the ES and $P$ values was a function of sample size. Power analysis before an investigation enhances the probability of ES and $P$ values producing similar interpretations of the data. Such a matching is desirable. However, power analysis is difficult in the absence of prior, similar investigations, as was the case in this investigation.

The post hoc and ES data indicated that there was a continuum of $\dot{V}_{\mathrm{O}_{2}}$ cost for the various class elements, with elements performed in an upright posture having a greater ${ }_{\mathrm{O}_{2}}$ than the floor elements (Table 1).
Furthermore, ES data suggested that the difference between the high-impact (circuit and jump) and low-impact elements was of practical significance (circuit $\approx$ jump $>$ low impact $>$ prone $>$ side/ supine). This difference between high and low impact elements is consistent with the findings of Williford et al. ${ }^{7}$.

While the $\dot{\mathrm{V}}_{2}$ values of the callisthenic elements were the lowest in this investigation, they had a greater mean(s.d.) $\dot{V}_{2}$ than the low-intensity, low-impact routines of Williford et al. (18(2) $\left.\mathrm{ml} \mathrm{kg}^{-1} \mathrm{~min}^{-1}\right)$, suggesting that not all upright elements have a greater oxygen cost than floor elements. The tempo of music used to pace the exercise does influence the $\dot{V}_{2}$ associated with a particular exercise-to-music routine $e^{3,4,7}$. In the Williford et al. ${ }^{7}$ investigation the tempo of the music used was 120 beats $\min ^{-1}$, while in the prone and side/supine tracks the tempo was 144 and 132 beats $\min ^{-1}$ respectively.

The $\dot{V} \mathrm{O}_{2}$ values for the upright elements of this study were similar to that reported by Williford et al. ${ }^{7}$ for high-intensity, high-impact aerobics, and by Otto et $\mathrm{al}^{\mathbf{4}}$ for high- and low-impact aerobics. However, the low-impact element of this investigation had a greater $\dot{V}_{\mathrm{O}_{2}}$ than the low-impact activities of Williford et $a .^{7}$ and Otto et al. ${ }^{9}$. Later Otto et al. ${ }^{4}$ partially attributed their low 1986 values to the relatively stationary nature of the routines used in that investigation. Other factors contributing to differences between upright elements include the level of arm involvement and the tempo of the music ${ }^{3,7}$.

Locomotion is often the goal of upright elements in an exercise-to-music session. The mean(s.d.) oxygen consumptions for walking (27.5(1.9) $\left.\mathrm{ml} \mathrm{kg}^{-1} \mathrm{~min}^{-1}\right)$, jogging $\left(30.9(2.4) \mathrm{ml} \mathrm{kg}^{-1} \mathrm{~min}^{-1}\right)$ and high intensity walking (34.0(2.9) $\left.\mathrm{ml} \mathrm{kg}^{-1} \mathrm{~min}^{-1}\right)$ at the pace typically found in an exercise-to-music session $\left(2 \mathrm{~m} \mathrm{sec}^{-1}\right)$ were found to be significantly different from one another ${ }^{2}$. The $\dot{V} \mathrm{O}_{2}$ associated with the low-impact element of this investigation and the high-intensity walking of Elliot et al. $^{2}$ were of a similar magnitude. Elliot et al. ${ }^{2}$ attributed the elevated oxygen cost of high-intensity walking to the exaggerated arm action and flexed support leg position. These characteristics are also common to low-impact routines.

The participants in this investigation were experienced exercise leaders and thus performed the movement sequences with a minimum of extraneous movement (i.e. they were efficient). Consequently, the $\dot{V}_{\mathrm{O}_{2}}$ values associated with these class elements may be greater in less experienced practitioners.

Heart rates are regularly used in the field to determine if an exercise regimen is sufficiently intense to produce an aerobic training effect. The American College of Sports Medicine (ACSM) ${ }^{16}$ states that heart rates between 65 and $90 \%$ of maximum are necessary to induce an aerobic training effect. However, there is evidence which suggests that heart rate may be an inappropriate index by which to gauge the intensity of exercise-to-music regimens. For example, at a given heart rate, exercise to music elicits a lower $\dot{V}_{\mathrm{O}_{2}}$ and oxygen pulse than running ${ }^{5}$. Stanforth et al. ${ }^{17}$ reported that the linear relationship between $\% \dot{V}_{\mathrm{O}_{2} \text { max }}$ and heart rate was 
only valid in exercise-to-music routines in which there was substantial lower limb involvement. Specifically, at a given heart rate, oxygen consumption was less in conditions where there was minimal lower limb involvement as opposed to substantial lower limb involvement. Our oxygen pulse data suggested that heart rate may not be a good index by which to compare the intensity of locomotor and callisthenic class elements. Oxygen consumption is the product of heart rate and oxygen pulse. The oxygen pulse for the callisthenic class elements was significantly less than the locomotor elements (Table 1). Consequently, for a given increase in heart rate there was a greater increase in the $\dot{V}_{\mathrm{O}_{2}}$ for the locomotor than the callisthenic elements. This suggests that heart rates should only be used to gauge the intensity of exercise within and not between movement elements.

In conclusion, the $\dot{V}_{2}$, heart rate and oxygen pulse associated with locomotor routines were greater than for the callisthenic elements. Heart rate appeared to be an appropriate index by which to gauge the intensity of exercise within, but not between, exercise-to-music elements. This resulted from differences in the oxygen pulse associated with the locomotor and callisthenic elements. There is a need to describe more exercise-to-music routines so that exercise prescriptions may more closely approximate the needs of the individual participant.

\section{References}

1 Bronstein M, Bishop P, May E, Conerly M, Smith J. Energy cost of low-impact aerobic dance with and without hand held weights. Med Sci Sports Exerc 1988; 20: S89.
2 Elliot BC, Morton AR, Johnston R. Biomechanical and physiological responses to modes of locomotion used in aerobic dance. Aust J Sci Med Sport 1991; 23: 90-5.

3 Hufhand $D$, Crowe L, Whaley M, Banning-Schaffner $P$. Metabolic responses to low-impact aerobic dance. Med Sci Sports Exerc 1988; 20: S88.

4 Otto R, Yoke M, Wygand J, Larsen P. The metabolic cost of multidirectional low impact and high impact aerobic dance. Med Sci Sports Exerc 1988; 20: S88.

5 Parker SB, Hanlon DP, Hurley BF, Vaccaro P. Failure of target heart rate to accurately monitor intensity during aerobic dance. Med Sci Sports Exerc 1987; 19: S29.

6 Williford HN, Blessing DL, Barksdale JM, Smith FH. The effects of aerobic dance training on serum lipids, lipoproteins and cardiopulmonary function. J Sports Med 1988; 28: 151-7.

7 Williford HN, Blessing DL, Olsen MS, Smith FH. Is low impact aerobic dance an effective cardiovascular workout? Phys Sportsmed 1989; 17: 95-109.

8 Yoke M, Otto R, Wygand J, Kamimukai C. The metabolic cost of two differing low impact aerobic dance exercise modes. Med Sci Sports Exerc 1988; 20: S88.

9 Otto RM, Parker CA, Smith TK, Wygand JW, Perez HR. The energy cost of low impact and high impact aerobic dance exercise. Med Sci Sports Exerc 1986; 18: S23.

10 Garrick JG, Requa RK. Aerobic dance: a review. Sports Med 1988; 6: 169-79.

11 Moore N, Banning-Schaffner P, Whaley M. The effects of 12 weeks of low impact aerobic dance training in sedentary and trained individuals. Med Sci Sports Exerc 1988; 20: S89.

12 Goss FL, Robertson RJ, Spina RJ, Auble TE et al. Energy cost of bench stepping and pumping light handweights in trained subjects. Res Q Exerc Sport 1989; 60: 369-72.

13 Cohen J. Statistical Power Analysis for the Behavioural Sciences. New York, USA: Academic Press, 1969.

14 Hedges LV, Olkin J. Statistical Methods for Meta-analysis. Orlando, Florida, USA: Academic Press, 1985.

15 Thomas JR, Salazar W, Landers DM. What is missing in p<.05? effect size. Res Q Exerc Sport 1991; 62: 344-8.

16 American College of Sports Medicine. Guidelines for Exercise Testing and Prescription. Philadelphia, USA: Lea and Febiger, 1986.

17 Stanforth D, Hamman C, Senechal C. Relationship of heart rate and oxygen consumption during low impact aerobic movements. Med Sci Sports Exerc 1988; 20: S88. 